\title{
TEMA DO ABORTO NAS AULAS DE SOCIOLOGIA
}

A Sociologia é uma área do conhecimento muito necessária para a compreensão do mundo moderno capitalista. Através dela pode-se discutir a realidade de forma científica, buscando compreensão e solução para os problemas sociais.

Em 1890, Benjamin Constant introduz a Sociologia no Brasil. Porém, com a sua morte, a disciplina não foi implantada. Isso só ocorre em 1925, passando a integrar o currículo do segundo grau do Colégio Dom Pedro II, no Rio de Janeiro, por iniciativa de Fernando de Azevedo. Reformas subseqüentes como as de Rocha Vaz, 1928, e Francisco Campos, 1931, ampliaram a inserção da Sociologia nas escolas de nível secundário.

Pode-se afirmar que a Sociologia se desenvolveu no Brasil a partir de 1933, com a fundação da Escola Livre de Sociologia e Política, da Faculdade de Filosofia, Letras e Ciências Humanas da Universidade de São Paulo, em 1934, e com a Faculdade de Filosofia do Rio de Janeiro, em 1935.

A Reforma de Gustavo Capanema, 1942, começou a restringir o ensino de Sociologia, tornando-o obrigatório apenas nas escolas normais, culminando com a retirada total da disciplina em 1964, exigida pela ditadura militar. Tal situação permaneceu até 1982 , quando foi promulgada a lei 7.044 e a resolução SE/236/83, ambas recomendando explicitamente sua inserção na grade curricular de forma optativa nas escolas de segundo grau.

A partir da promulgação da nova Lei de Diretrizes e Bases LDB, a Sociologia, enquanto disciplina ministrada no Ensino Médio, encontra-se ameaçada. A nova LDB deixou margem para várias interpretações, pois a Lei não regulamenta a disciplina como parte obrigatória do currículo.

O ensino de Sociologia tem colaborado para o despertar do senso crítico dos alunos bem como tem ajudado a desenvolver atividades que colaboram para o efetivo exercício da cidadania. Retirar essa disciplina da grade curricular consistiria em um enorme prejuízo à formação de nossa juventude, quando se carece tanto que

A AUTORA

\section{Márcia Regina Viotto}

Professora de Sociologia na Escola Estadual de Ensino Médio Prof. Américo de Moura - São Paulo. 
a escola desempenhe o papel de formação de uma consciência democrática e de respeito ao outro.

Aqui, relato minha experiência como professora de jovens do segundo ano do Ensino Médio da Escola Estadual Professor Américo de Moura, situada na região Leste, da Capital de São Paulo.

\section{ABORTO: UM TEMA POLÊMICO}

Ao observar nossa juventude preocupa-me, e muito, a falta de conhecimento a respeito da sexualidade e as consequiências oriundas de comportamentos baseados apenas nas informações do senso comum. A adolescência não tem formação nenhuma e padece com informações distorcidas, na maior parte das vezes originadas de orientações religiosas que reprimem a partir de dogmas e não levam em conta a triste realidade social.

No primeiro bimestre de 1998, nas aulas de Sociologia, já havia trabalhado conceitos como o de trabalho e seu poder de transformação para fazê-los compreender melhor os diferentes tipos de conhecimento que permeiam nossa consciência. $\mathrm{O}$ homem, ao transformar a natureza, transforma-se a si mesmo e cria toda uma civilização. A relação homem/ natureza/ cultura é garantida pelo trabalho. O constante desafio da vida faz com que o homem busque explicações para tudo, mesmo que seja no seu imaginário e na fé (chamada consciência mítica); na sua dúvida sobre os valores e busca da verdade (consciência filosófica); ou na busca da verdade através de conhecimento e provas (consciência científica) ${ }^{1}$. Todos esses tipos de consciência existem em nossa sociedade. O saber está vinculado ao processo de produção de uma determinada sociedade. Passamos a relacionar este saber com o tempo histórico e, a partir daí, a caracterizar suas diferentes formas. Compreender como o ser humano se apropria da natureza e a representa significa perceber as várias concepções de mundo existentes e sua presença na sociedade atual.

Deparei-me, então, com uma juventude com poucos conhecimentos históricos e enorme resistência ao conhecimento científico. Encontrei uma consciência mítica muito forte, fruto da falta de acesso às informações e ao conhecimento científico já acumulado; e uma consciência filosófica em pleno desenvolvimento, própria do ser jovem. Percebi a enorme dificuldade dos alunos em compreender a metodologia científica para o conhecimento da realidade, principalmente quando se tenta compreendê-la a partir de suas próprias origens, ou seja, a realidade brasileira. 
No terceiro bimestre, trabalhamos um dos clássicos da Sociologia, Emile Durkheim ${ }^{2}$. Pensador francês, iniciador da Sociologia enquanto Ciência, viveu em uma época de mudanças importantes como a Comuna de Paris, 1871, e a Primeira Guerra Mundial, 1914-1918. Episódios que marcaram o fim de valores ligados ao colonialismo, impondo o pensamento democrático burguês e afirmando o estabelecimento de uma nova ordem social. Durkheim lutou para provar que a Sociologia é uma ciência e defendeu a neutralidade diante dos fatos sociais, isto é, acreditava que ela não se deveria envolver com a Política. Outra idéia importante defendida por Durkheim era que através da violência não se combate a violência e nem se pode criar uma nova sociedade. Todos os problemas deveriam ser resolvidos dentro da ordem e do progresso. Durkheim "admitia que o capitalismo é a sociedade perfeita: trata-se apenas de conhecer os seus problemas e buscar uma solução científica para eles"3.

(....) "A sociedade é um conjunto de normas de ação, pensamentos e sentimentos que não existem apenas nas consciências dos indivíduos, mas são construídas exteriormente, isto é, fora das consciências individuais. Na vida em sociedade o homem defrontase com regras de conduta que não foram criadas diretamente por ele, mas que existem e são aceitas na vida em sociedade, devendo ser seguidas por todos. Sem essas regras, a sociedade não existiria e é por isso que os indivíduos devem obedecer a elas. As leis são expressão maior das regras e o indivíduo isolado não cria as leis e nem pode modificá-las. São as gerações que vão criando e reformulando coletivamente as leis. Como indivíduos isolados, temos de aceitá-las sob a pena de sofrer castigos por violá-las" 4 .

Durkheim foi influenciado pelas obras de Augusto Comte e Hebert Spencer, iniciadores do Positivismo. Partindo de sua concepção funcionalista da sociedade, encontrei o gancho para o trabalho aqui apresentado, pois suas idéias são muito presentes em nossa sociedade.

Tentei, então, mostrar o poder da consciência coletiva existente na sociedade, como ela é criada e, partindo de uma concepção histórico-crítica, demonstrar a força do poder econômico, aliado ao poder político e ideológico, os quais criam um universo cultural em cada país, influenciando cada um de nós. Ao começarmos o trabalho pelo conhecimento do mundo capitalista, a discussão do aborto possibilitaria entender, ao mesmo tempo, o sistema em que vive-

2. DURKHEIM, E. (1858-1917) Chamado de pai da Sociologia. Suas principais obras são: A divisão do trabalho social (1893); As regras do Método Sociológico (1895); O suicídio (1897); As formas elementares da vida religiosa (1912), entre outras. (N.Ed.)

3. MEKSENAS, P. Sociologia. 2. ed. São Paulo: Cortez, 1994. p. 68. (Coleção Magistério.)

4. TOMAZI, N. D. Iniciação à Sociologia. São Paulo: Atual, 1993. p. 18. 
mos, de desigualdades entre as classes sociais, o humano como mercadoria, vítima e, ao mesmo tempo, sujeito da História. Neste contexto, fomos procurando discutir a questão da cidadania em seu sentido mais profundo, a partir do qual o ser humano não é apenas integrante da História, mas sim elemento fundamental na construção da sociedade humana.

\section{ABORTO: SOMOS CONTRA?!}

Durante dois anos, trabalhei em uma escola da periferia da capital onde o índice de meninas grávidas chegou, no ano de 1997, a $10 \%$ das adolescentes matriculadas, entre 11 e 18 anos.

Ao falarmos sobre um assunto de interesse geral, curioso, tabu, desconhecido e polêmico como o aborto, a resistência logo apareceu: somos contra!

"O aborto é a terceira causa de morte materna no Brasil. Milhares de mulheres morrem todos os anos, vítimas de complicações decorrentes de abortos malfeitos, outras tantas ficam estéreis e a sociedade ainda as condena. (....) $\mathrm{O}$ direito ao aborto é previsto por lei desde 1940. (....) No Brasil apenas sete hospitais possuem Serviço de Aborto legal (....) Queremos tão-somente garantir-lhes o direito à escolha", declaram a socióloga Guacira Cesar de Oliveira e a jornalista Katia Souto 5 .

Meu objetivo era o de introduzir a discussão do tema no sentido de torná-los sabedores da realidade brasileira. Seria um ganho se tomassem contato com o assunto e ficassem com algumas questões claras, tais como: a existência da lei; os preconceitos em torno da mulher; a mulher no mundo capitalista; a religião e seu poder; o aborto como prática cotidiana na sociedade brasileira, tendo como consequiência a morte de milhares de mulheres; a discussão sobre a legalização; o alto índice de adolescentes grávidas e que abortam.

Travei a seguinte discussão: não se tratava, a princípio, de ser contra o aborto ou a favor dele. Tratava-se simplesmente de tomar conhecimento de forma científica, conhecer para depois formar opinião. Era preciso estar aberto para obter novos conhecimentos. A minha preocupação foi a de possibilitar um certo aprofundamento e discussão sobre o assunto. Trabalhei com quatro segundas séries do Ensino Médio, cerca de 120 alunos que formaram grupos, com três elementos cada. 


\section{MÍDIA E JOVENS}

A informação que chega à juventude é, na grande maioria das vezes, via TV. A mulher é apresentada freqüentemente como o sexo frágil, o objeto de desejo, a dona de casa, a submissa e a inferior. Mundo onde o homem pode tudo e a mulher bem pouco. $\mathrm{O}$ corpo feminino é mostrado como objeto de sedução.

Vivemos em um país onde a beleza é fundamental. A mídia cria um mundo imaginário que fragmenta as pessoas. O Brasil parece que tem um principal produto de exportação: a mulher. Essa é uma imagem bastante explorada para atrair turistas. As adolescentes, inspiradas nesse massacre televisivo, começam cada vez mais a se produzirem para despertar o desejo do outro o homem -, que passa a ser a condição necessária para a sua própria aceitação e razão de ser. Ter um homem consigo parece ser a principal conquista que a mulher tem a fazer. $\mathrm{O}$ seu objetivo maior parece ser, apesar de todas as transformações ocorridas nas últimas décadas, casar e ter filhos - um romance sempre com final feliz. É comum nas novelas, com altos índices de audiência, cenas nas quais o namoro aparece como se não houvesse nenhuma conseqüência. É um mundo onde não há doenças sexualmente transmissíveis e bem pouco se fala da AIDS. Não há, por parte da mídia, nenhuma grande discussão que vise a educar. De vez em quando, de tempos em tempos, aparece uma programação que acena para algo mais interessante: é o caso do seriado Mulher que a Globo tem exibido. Aí fica claro como a mídia poderia colaborar com a opinião pública, discutindo os temas tabus que estão presentes em nosso cotidiano. Mas essa ainda não é a regra, na disputa pela audiência a mídia extrapola. Pouca importância é dada à qualidade da programação, o que vale é o quanto se lucra.

Sem dúvida, nossos adolescentes ficam completamente perdidos, pois quando é necessário ter orientação clara para um assunto como o aborto, seus pais, na maioria das vezes, têm grandes dificuldades em abordar o tema tabu e pouco se contrapõem ao senso comum e, quando o abordam, normalmente é para dar broncas e fazer proibições. Por sua vez a escola, que seria um dos lugares apropriados para a discussão, não possui, em seu currículo, orientação adequada e acaba sobrando para os professores de Ciências e Biologia, quando esses se dispõem a fazer o trabalho. 
Somente a informação, tornada conhecimento ${ }^{6}$, pode se contrapor ao senso comum. Condição necessária para que as pessoas possam melhor enfrentar a vida. O Brasil faz parte dos nove países em desenvolvimento mais populosos e com maior taxa de analfabetismo. É fato que a educação é problemática para todos, mas para as mulheres é ainda pior. Constata-se hoje que, num total de 900 milhões de analfabetos no mundo, dois terços são mulheres. Dados assustadores que demonstram o quanto a mulher ainda é discriminada na sociedade.

\section{DESENVOLVIMENTO DO TRABALHO}

Na primeira etapa, orientei os grupos a partirem da mídia, observando através de seus vários meios como ela apresentava o problema. Poderiam também fazer entrevistas, as mais diversas, com pessoas entendidas do assunto, como médicos, advogados, organizações feministas etc., como também poderiam entrevistar pessoas que já haviam praticado o aborto e, ainda, pesquisarem vídeos e outras bases de informação.

$\mathrm{Na}$ segunda etapa, orientei os alunos a organizarem a pesquisa de forma científica. O grupo deveria fazer a leitura e o confronto de todas as informações encontradas. Posteriormente, deveriam discutir e refletir sobre o assunto, formulando suas opiniões. Para acompanhar o desenvolvimento do trabalho solicitei que respondessem às seguintes questões: a) Segundo a definição de Durkheim, aborto seria um fato social, faz parte da consciência coletiva da sociedade brasileira? b) Diante da moral dominante no Brasil, Durkheim consideraria o aborto um fenômeno normal ou patológico? c) O grupo é a favor ou contra o aborto, e qual a opinião sobre a liberação? Justifique com dados científicos.

Na terceira etapa, orientei-os para o debate, visando à ampliação e consolidação dos conhecimentos. Então formulei 15 questões que lhes possibilitariam organizar melhor o trabalho até ali executado e, então, em sala de aula, faríamos um debate. Por fim, promovemos uma palestra sobre o assunto, depois da qual fechamos o tema com uma análise e reflexão individuais.

As questões foram:

1 - Como são vistos nossos corpos - do homem e da mulher na sociedade?

2 - Como é tratada a questão do sexo?

6. Ver sobre o assunto: BACCEGA, M. A. Conhecimento, informação, tecnologia. Comunicação \& Educação. São Paulo: CCA-ECA-USP/Moderna, n. 11, jan./abr. 1998. p. 7-16. (N.Ed.) 
3 - No Brasil, há planejamento familiar?

4 - Quais são os métodos anticoncepcionais existentes?

5 - Todos têm acesso aos métodos anticoncepcionais e sabem como usá-los?

6 - Como é vista a questão da maternidade?

7 - Como é vista a questão do aborto no Brasil?

8 - Quem são as mulheres que praticam o aborto, quais suas razões?

9 - Quais as conseqüências do aborto?

10 - Como as religiões enxergam o aborto? (Catolicismo, Judaísmo, Espiritismo, Hinduísmo, Budismo, Protestantismo, Islamismo e outras). Resuma cada uma delas.

11 - O que pensam os homens e as mulheres sobre o aborto?

12 - A questão do controle do aborto estaria vinculada aos interesses demográficos que tem um país?

13 - Breve história da anticoncepção, desde os tempos antigos até hoje.

14 - O que fala o Código Penal no Brasil?

15 - A mídia e a questão do aborto.

16 - Análise e reflexões sobre o tema (individual).

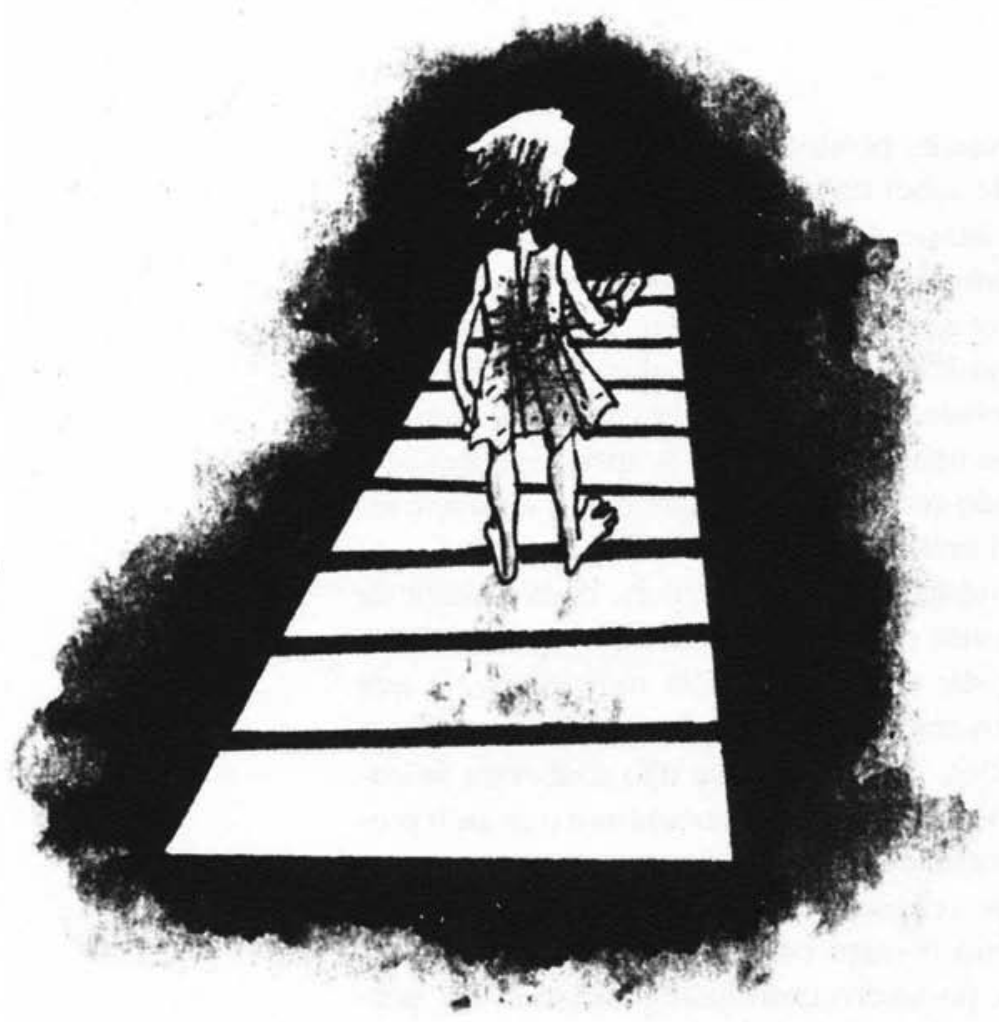




\section{PESQUISA}

É interessante observar o empenho dos alunos na procura do material e ver que vários grupos tiveram acesso à Internet, através da qual puderam ter as mais distintas fontes de informações, da religião, da medicina formal, da análise filosófica e científica. Muitas entrevistas foram feitas com advogados, médicos, além de entrevistas com mulheres que já praticaram o aborto. Ouvirem a parte médica, a legal e, também, as razões de quem aborta ou sofre o aborto permitiu uma maior reflexão e análise por parte dos alunos. Fizeram ainda leituras organizadas. Livros didáticos e enciclopédias foram fontes importantes, pois oferecem um conhecimento sistematizado. Outras fontes importantes foram artigos de jornais e revistas de atualidades que trataram do tema. Os alunos puderam tomar contato com muitas informações e descobrir coisas como, por exemplo, o aborto acontece em todas as classes sociais, mas as mortes ocorrem nas camadas pobres. $\mathrm{O}$ depoimento das pessoas relatando suas experiências, seus dilemas, seus preconceitos, suas posições, mais próximas do cotidiano, ajudaram também na reflexão dos alunos. O contato com tantas fontes e ampla bibliografia deixou claro para eles que o assunto é complexo e que para se formar uma opinião a respeito é preciso pesquisar e estudar.

\section{RESULTADOS}

Considerei extremamente positivo o trabalho, pois os alunos tiveram a oportunidade de saber tudo que queriam, através de sua própria pesquisa. Deram ênfase à sua curiosidade. Perceberam como a sociedade é desinformada e como é forte a postura segundo a qual, sem mesmo conhecer o assunto, a princípio se posiciona contra o aborto. A ausência, omissão ou a presença dos meios de comunicação têm peso neste debate. Fica clara a necessidade de se tratar do assunto na escola. O reconhecimento, pela própria vivência pessoal, de que o sexo é tratado como tabu, e de que o que se sabe é insuficiente, já significa um grande ganho.

Com o debate aprenderam ainda mais pois, com a troca de idéias, perceberam que, entre eles, nem todo mundo pensa igual perceberam que pode existir uma consciência individual - e que aqueles que realmente estiveram abertos a aprender, foram capazes de argumentar suas opiniões. Já, aqueles que não souberam se colocar, perceberam a fragilidade de seus pensamentos e o quanto precisam conhecer para formular opiniões.

A marca do discurso religioso deu, inicialmente, o tom das conversas, mas ao tomarem contato com as informações colhidas através de diversas fontes, podendo confrontá-las e discuti-las, per- 
ceberam a necessidade de refletirem e tornarem-se mais flexíveis em suas posições iniciais.

Tenho certeza de que todos ganhamos ao tratar de um assunto tão polêmico e tão importante quanto o aborto.

\section{REFLEXÕES DOS ALUNOS}

Se a informação fosse maior e se todos tivessem a oportunidade de discutir, como nós tivemos, as mulheres não morreriam em virtude do aborto.

\section{Lívia Gibertoni (aluna do segundo ano J)}

As mulheres católicas que defendem o direito da mulher de escolher estão agindo com a alma de mulher, mas acima de tudo de ser humano.

Cláudia Barbosa Manzano (aluna do segundo ano J)

Apesar de eu ser contra o aborto, concordo que, antes de recriminar a mulher que deseja abortar, devemos escutar, saber qual (ou quais) o(s) motivo(s) que a levou (levaram) a tomar tal decisão.

Marcelle E. Assato (aluna do segundo ano J)

Pelo que estive analisando e observando, as pessoas se apegam muito à religião; talvez por ser uma decisão difícil de ser tomada, preferem ouvir as opiniões da Igreja do que seguirem sua própria consciência. Vivemos em uma sociedade que discrimina quem pratica o aborto, sem ao menos saber o motivo pelo qual a pessoa o praticou. Não seria bem mais fácil que a legalização do aborto fosse realizada? Evitaríamos a morte de milhares de mulheres que, sem ter a quem recorrer, preferem entregar-se nas mãos de médicos que lucram com a desgraça alheia! (...) Temos que abrir nossas cabeças, prevenir sem dúvida é a melhor solução.

Ana Paula Freitas Marcelino (aluna do segundo ano J)

Acho muito legal essa idéia de discutir o aborto e até outros temas em sala de aula, pois muitas vezes há falta de informações, principalmente nas camadas mais pobres, sobre essa questão. Assim posso pensar duas vezes antes de praticar uma relação sexual, já pensando nas conseqüências.

Míriam Batista Queiroz (aluna do segundo ano J)

A mulher na sociedade é muito recriminada: todos pensam que se houve uma gravidez indesejada foi culpa dela, pois foi ela que provocou, assediou etc...

Alexandra Dias Paz (aluna do segundo ano I) 
A partir do momento em que o assunto aborto for esclarecido de maneira aberta e democrática, os problemas serão menores, fazendo com que as pessoas possam tomar a sua decisão sem medo de que a sociedade a magoe.

Sérgio Rodrigo da Silva (aluno do segundo ano I)

Antes de conhecer o assunto eu tinha a opinião de que o aborto era um crime, que estava tirando uma vida, mas, depois de tudo, vi que não é bem assim, as mulheres é que têm o direito de decidir e que, também, apenas em caso de estupro e quando a gravidez é de risco para a mulher ou para o bebê o aborto seria legal.

Gina da Silva (aluna do segundo ano $\mathrm{H}$ )

Após a pesquisa que fiz e a palestra que presenciei, acredito que quando se fala do aborto a sociedade deve participar, mas a escolha mesmo, se a mulher deve ou não interromper a gravidez, seja qual for o motivo, é uma decisão individual, pois o aborto não constitui algo criminoso, mas sim um direito que cada mulher possui sobre si mesma.

Manoela Marques Silva (aluna do segundo ano L)

Apesar de ser tão difícil tomar uma posição em relação ao aborto, eu penso que uma mulher deve estar psicologicamente $e$ monetariamente preparada para ser mãe; se não for assim, ela deve ter o direito de abortar, afinal o útero é dela ou não é?

As leis são desfavoráveis ao aborto, as religiões são contra e a sociedade o condena. Todos esses fatores prejudicam as mulheres que estão com problemas, impedindo-as de abortar.

Ana Paula Pineiro Villanueva (aluna do segundo ano L)

Resumo: Relato de experiência de uma professora do Ensino Médio, desenvolvida em uma escola pública da região Leste da Capital paulista que, a partir dos conceitos básicos de Durkheim, introduz pesquisa e debate sobre o tema do aborto nas aulas de Sociologia. A professora orienta pesquisa dos alunos em diversas fontes: desde jornais e revistas da grande imprensa, páginas na Internet, livros didáticos, artigos científicos até entrevistas com médicos, advogados e com mulheres que já tenham praticado aborto. $\mathrm{O}$ objetivo deste trabalho é o de propiciar aos alunos a formulação de opinião baseada em fatos e dados científicos, fazendo com que eles extrapolem o senso comum e a visão dogmática.

Palavras-chave: aborto, ensino de Sociologia, Ensino Médio, direito da mulher
Abstract: Report on the experience of a High School teacher, carried out in a public school of the Eastern São Paulo City area which, based on the Durkheim principles, introduces research and debate on the abortion theme into Sociology classes. The teacher guides student research in several sources, ranging from newspapers and magazines, Internet pages, didactic books, to scientific articles and even uses interviews with doctors, lawyers and women who have already had abortions. The goal of this work is to give the students a possibility to form opinions based on fact and on scientific data, making them go beyond common sense and dogmatic views.

Key words: abortion, teaching of Sociology, High School Teaching, women's rights 